\title{
Editorial - A crisis in social care: time for rethinking?
}

\section{Rachel Perkins and Julie Repper}

\section{A crisis in social care: time for rethinking?}

Barely a day goes by without news headlines talking about "the crisis in social care", brought into sharp focus by both COVID-19 and Brexit. Staff shortages are making many services, both residential and community, unsustainable, and the availability of social care has decreased. It is unquestionable that resources are a serious issue, but we believe that a more fundamental rethinking is required.

In October 2020, Skills for Care estimated that, on any given day, there are around 112,000 vacancies in the social care sector and an annual staff turnover rate in excess of $30 \%$ (430,000 people) (Bottery and Ward, 2021). The post Brexit "points based" immigration system does not list "care worker" as an eligible occupation on the "skilled worker" route; therefore, from January 2021, care workers cannot immigrate to take up these roles, and the pay for such workers falls well below the necessary salary threshold [1]. Although the pay rates have increased since 2014 , this is largely due to increases in the minimum wage, now renamed "national living wage". In 2019/20, the average care worker was paid £8.50 per hour in the independent sector (Bottery and Ward, 2021). In April 2021, this average rose with an increase in the "national living wage" to $£ 9.20$ per hour but remains $28 \%$ lower than the UK's national average salary [2] and below the "real living wage" of $£ 9.50$ (10.85 in London) [3]:

People can now earn more working in supermarkets and cleaning than as care workers. (Bottery and Ward, 2021, p. 26)

With the financial pressures that continue to face local authorities, it is unlikely that the funds will be available to raise care workers' pay to the level which the importance of their work merits.

Much of the current media concern about social care has focussed on older people, especially older people living in residential and nursing homes. Relatively less attention has been paid to the crisis in support provided to older people in their own homes and to younger people with physical health conditions and impairments and learning disabilities, and relatively no attention has been paid to the social care needs of people with mental health challenges. The 2020 national community mental health survey (CQC, 2020) showed that the social support needs of people with mental health challenges often go unmet:

- In terms of help with benefits and finances, 30\% said they had definitely received help, but $43 \%$ said that they would have liked help but did not get it.

- In terms of help to get or keep work, $27 \%$ said they had definitely received help, but $43 \%$ said they would have liked help but did not get it.

- In terms of community and social activities, 32\% said they had definitely received help, but $37 \%$ said they would have liked help but did not get it. In terms of support with accommodation, the national community mental health surveys no longer ask questions about accommodation, but in 2015, 34\% said they definitely received help; $42 \%$ said they would have liked help but did not get it.

Overall, the number of requests for social care has risen, but the number of people actually receiving care receiving social care has fallen:
Rachel Perkins is Senior Consultant at ImROC London, UK. Julie Repper is Director at ImROC, London, UK. 
Between 2015/16 and 2019/20, 120,000 more people requested social care support but around 14,000 fewer people received either long- or short-term support. (Bottery and Ward, 2021, p. 3)

This is largely as a consequence of the financial pressures on local authorities that predated COVID-19 (Bottery and Ward, 2021): funding for local authorities fell by 55\% from 2010/11 to 2019/20 (Controller and Auditor General, 2021). Not only have many people been refused social care, many have seen their social care packages cut so that they focus only on the essentials that keep people alive rather than also providing support for those things that make life worthwhile:

Liverpool turned down $31 \%$ of the near 3,500 requests for social care, while reducing the hours carers spend with 194 working-age adults and 223 elderly people in the city. Birmingham turned down a quarter of its 18,500 requests for social care and Solihull rejected $27 \%$. (Wall, 2021, p. 2)

The 2014 Care Act [4] imposes on local authorities a duty to promote an individual's wellbeing, where well-being is defined in terms of nine principles [5]:

1. personal dignity (including treatment of the individual with respect);

2. physical and mental health and emotional well-being;

3. protection from abuse and neglect;

4. control by the individual over day-to-day life (including over care and support provided to the individual and the way in which it is provided);

5. participation in work, education, training or recreation;

6. social and economic well-being;

7. domestic, family and personal relationships;

8. suitability of living accommodation; and

9. the individual's contribution to society.

It states that the local authorities must carry out an assessment of anyone who appears to require care or support, focus the assessment on the person's needs and how they impact on their well-being and the outcomes they want to achieve, involve the person in their assessment and provide access to an independent advocate to support the person's involvement [6]. Further, it states that the local authority must begin with the assumption that the individual is best placed to judge their well-being and have regard for their views, wishes, feelings and beliefs [7]. As Warren (2020) says:

Social care should be about helping people live the lives they want to live. (Warren, 2020, p. 3)

Yet, how many people living with mental health challenges, or older people, or people living with other health conditions and impairments, can honestly say that these ambitions have been achieved? There is a need to not only finance social care properly but also to fundamentally rethink the purpose of social care. Is it about looking after the vulnerable, or is it about enabling people to live the lives they want to lead?

Although the underfunding of social care is very real and very important, the challenge is not simply financial. We need to re-vision social care and invest in an approach that allows people to live meaningful, valued and satisfying lives. Social Care Future [8] is a movement of people who have come together to do exactly this: develop a new framing of, and vision for, social care:

Social Care Future describes the dominant framing of a social care system [...]:

[...] which fails to look after vulnerable people adequately, leaving them to be neglected and abused, is broken and in or on the brink of a crisis. The cost of social care is spiralling because there are growing numbers of older and disabled people and funding hasn't kept pace with demand. Councils, the NHS and providers are under severe strain. The system can't cope. Other valuable services are threatened. 
Only government can solve this. But governments for the past 20 years have failed to. This government's Green Paper, which keeps being delayed, probably won't change anything. We need an extra £3.5 billion immediately to 'plug' the gap but it's nowhere near enough to truly fix things. If you need care today you will lose your home to pay for it and it will still be terrible. (Crowther, 2019, pp. 9-10)

This prevailing narrative around social care divides people into "them" and "us" - ordinary citizens and the "vulnerable" (older people, disabled people including people living with physical and mental health conditions). Social care is for "the vulnerable" and is about being "looked after"/"cared for" by services: a safety net rather than a springboard to a decent life. The focus is on the challenges facing the social care "sector" (and shoring up the existing paternalistic system) rather than benefitting the individuals and communities that use it.

The real challenge is to reframe the social care enterprise and invest in coproducing "a reciprocal web of community based support [...] rooted in social justice, equality and rights [...] [that] better supports people to lead good lives [...] [...] [and from which] everyone stands to benefit." (Crowther, 2019 pp. 10-11)

Social Care Future (2021) describes an alternative vision:

We all want to live in the place we call home with the people \& things that we love, in communities where we look out for one another, doing the things that matter to us.

They conducted an inquiry that received responses from over 500 people and identified five key changes necessary to bring about this vision:

1. communities where everyone belongs;

2. living in the place we call home;

3. leading the lives we want to live;

4. more resources, better used; and

5. sharing power as equals.

By investing together we can create a fair, reliable and effective social care support for everyone. (Crowther, 2019, p. 56)

This vision very much resonates with recovery-focused transformation in the mental health sphere: a focus on the person in the context of their life and community where treatment and support are seen not as an end in themselves but as a means to enable people to live the lives they want to lead (see, Repper and Perkins, 2003, 2012). It is also a vision that has been voiced in the context of services more broadly:

Everywhere I see the mistake of ignoring that people have priorities in their lives besides merely surviving another day. Even in severe illness or frailty, people desire connections to others and to purposes of their own choosing.

I think we've been wrong, I think we've been rather limited about what we think our job is in building systems of care for human existence. We think our job is to ensure health and survival. But really it is larger than that. It is to enable well-being - and well-being is ultimately about sustaining the reasons one wishes to be alive. (Gawande, 2014, p. 7)

In the mental health domain, there may be other destructive narratives that need addressing in relation to social support, especially narratives around dependence and independence. In mental health services, the prevailing narrative is that "being dependent" is a "bad thing" and "fostering dependency" is to be avoided. The goal is to render people "independent" - selfreliant - which invariably means doing things without help and being discharged from services. These ideas are embedded in the Mental Health Recovery Star (MacKeith and Burns, 2011) where progress is defined and measured on a "ladder of change" moving from 
stuck" ("not feeling able to face the problem or accept help" MacKeith and Burns, p. 2) through to "self-reliance" ("the point when we can manage without help" MacKeith and Burns, p. 2). Indeed, they reflect the "clinical model" on which mental health services are founded: the goal is to change people so that they "fit in" via therapy, skills training, time limited support, etc. It is assumed that support will be temporary until the person can do things unaided and ignores the reality that many mental health challenges recur or are ongoing.

Instead, we need a social- and rights-based approach to inclusion, which focuses on the barriers a person faces and the adjustments and supports needed to enable people to do the things they value and live the life they wish to lead:

The real problem exists in the form of barriers in the environment that prevent us living, working and learning in environments of our choice. [The task is] to confront, challenge and change those barriers to make environments accessible [...] If we remember that environments are not just physical places but also social and interpersonal environments, then it is clear that those of us with psychiatric disabilities face many environmental barriers that thwart our efforts to [...] gain control over our lives and the resources that affect our lives. (Deegan, 1992, p. 11)

The issue is not one of "independence = good" and "dependence = bad"; instead, the question is whether the support that is provided enables people to do the things they value or whether it prevents people from using their talents and living the life they wish to lead:

Inclusion and citizenship are not about 'becoming normal' but creating inclusive communities that can accommodate all of us. Not about 'becoming independent' but having the right to support and adjustments (in line with our choices and aspirations) to ensure full and equal participation and citizenship (Slade et al., 2013 p. 14).

Perhaps we need to question the very concept of social "care", which conjures images of being "looked after" (cared for) and "protected" from the world. Perhaps "social support" might better describe the assistance that all of us may need to do the things we value and live the lives we wish to lead?

Everyone need support at some time or another if they are to pursue their dreams and ambitions. Sometimes this support may come from services, but equally it comes from family, friends, neighbours and the ordinary resources available in our communities. (Repper and Perkins, 2012, p. 75)

\section{Notes}

1. www.gov.uk/government/publications/uk-points-based-immigration-system-employer-information/ the-uks-points-based-immigration-system-an-introduction-for-employers

2. https://uk.jobted.com/salary/carer

3. www.livingwage.org.uk/what-real-living-wage

4. www.legislation.gov.uk/ukpga/2014/23/contents/enacted

5. www.legislation.gov.uk/ukpga/2014/23/part/1/crossheading/general-responsibilities-of-local-authorities/ enacted

6. www.scie.org.uk/care-act-2014/assessment-and-eligibility/

7. www.legislation.gov.uk/ukpga/2014/23/part/1/crossheading/general-responsibilities-of-local-authorities/ enacted

8. https://socialcarefuture.blog

\section{References}

Bottery, S. and Ward, D. (2021), Social Care 360, Kings Fund, London.

Care Quality Commission (2020), 2020 Community Mental Health Survey, Statistical release, CQC, London. 
Crowther, N. (2019), Talking about a Brighter Social Care Future \#Socialcarefuture, In Control Partnerships, Solihull.

Deegan, P. (1992), "The independent living movement and people with psychiatric disabilities: taking back control over our lives", Psychosocial Rehabilitation Journal, Vol. 15 No. 3, pp. 3-10.

Gawande, A. (2014), "^the idea of wellbeing", Lecture 4 in the Reith Lectures 2014: The Future of Medicine, Indian International Conference Centre New Delhi, 20th December 2014, available at: http://downloads.bbc. co.uk/radio4/open-book/2014_reith_lecture_4_delhi.pdf (accessed 25 September 2021).

MacKeith, J. and Burns, S. (2011), Mental Health Recovery Star. User Guide, Mental Health Providers Forum and, London.

Repper, J. and Perkins, R. (2012), "Recovery: a journey of discovery for individuals and services", Chapter 7 in Phillips, P., Sandford, T. and Johnston, C. (Eds), Working in Mental Health: Practice and Policy in a Changing Environment, Routledge, Oxford.

Repper, J.M. and Perkins, R.E. (2003), Social Inclusion and Recovery: A Model for Mental Health Practice, Balliere Tindall, London.

Social Care Future (2021), Whose Social Care is It Anyway? From Permanent Lockdown to an Equal Life, In Control Partnerships, Solihull.

Wall, T. (2021), "We're being impoverished': how English councils have cut care during the pandemic", The Guardian, Wed 6 Jan 2021, available at: www.theguardian.com/society/2021/jan/06/were-beingimpoverished-how-english-councils-have-cut-care-during-the-pandemic (accessed 25 September 21).

Warren, S. (2020), Social care reform: fit for purpose or simply fit for a crisis? Blog 14th May 2020, The Kings Fund, London, available at: www.kingsfund.org.uk/blog/2020/05/social-care-reform-fit-purposeor-crisis (accessed 24 September 21).

\section{Further reading}

Comptroller and Auditor General (2021), The Adult Social Care Market in England, National Audit Office, London.

Slade, M., Amering, M., Farkas, M., Hamilton, B., O'Hagan, M., Panther, G., Perkins, R., Shepherd, G., Tse, S. and Whitley, R. (2014), "Uses and abuses of recovery: implementing recovery-oriented practices in mental health systems", World Psychiatry, Vol. 13 No. 1, pp. 12-20. 